\title{
Investigation of a plain ball burnishing process on differently machined Aluminium EN AW 2007 surfaces
}

\author{
Marco Posdzich ${ }^{1}$, Rico Stöckmann ${ }^{1}$, Florian Morczinek ${ }^{1}$, and Matthias Putz ${ }^{2}$ \\ ${ }^{1}$ Chemnitz University of Technology, Institute for Machine Tools and Production Processes (IWP), Reichenhainer Str. 70, 09126 \\ Chemnitz, Germany \\ ${ }^{2}$ Fraunhofer Institute for Machine Tools and Forming Technology IWU, Reichenhainer Str. 88, 09126 Chemnitz, Germany
}

\begin{abstract}
Burnishing is an effective chipless finishing process for improving workpiece properties: hardness, vibration resistance and surface quality. The application of this technology is limited to rotationally symmetrical structures of deformable metals. Because of the multiaxial characteristics, the transfer of this force controlled technology on to prismatic shapes requires a comprehensive process development. The main purpose of this paper is the characterization of a plain burnishing process on aluminium EN AW 2007 with a linear moved, spherical diamond tool. The method of design of experiments was used to investigate the influence of different machined surfaces in conjunction with process parameters: burnishing force, burnishing direction, path distance and burnishing speed. FEM simulation was utilized for strain and stress analysis. The experiments show, that unlike the process parameters the initial surface roughness as $3 \mathrm{rd}$ order shape deviation does not have a significant influence on the finished surface. Furthermore a completely new surface is created by the process, with properties independent from the initial surface roughness.
\end{abstract}

Keywords: Rolling, Micro forming, Free forming

\section{Introduction}

Burnishing is a force controlled forming process, which is widely applied on finishing of rotationally symmetrical parts e.g. found in the automotive industry. A burnishing tool is pressed under a force onto the workpiece surface for this finishing process. As seen in Fig. 1 a tangential sliding or rolling of the tool deforms the material at the surface, which results in a reduction of the roughness [1]. At the same time an increase in compressive residual stress at the boundary layer is

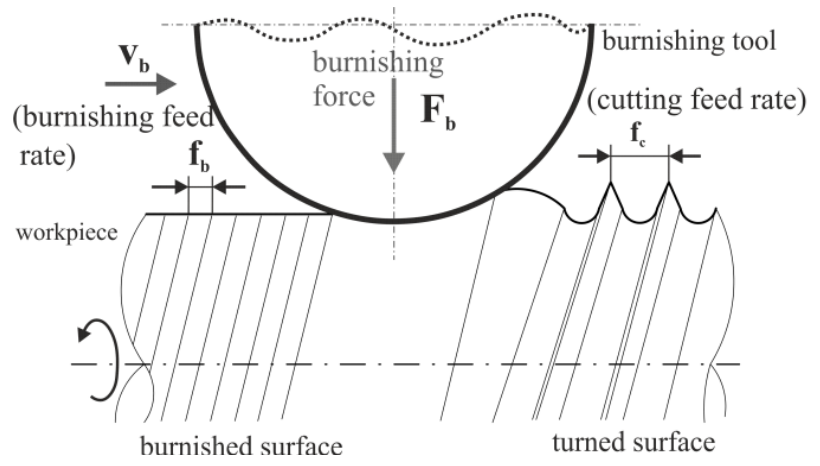

Fig. 1. Schematics of a burnishing process on a turned surface

achieved, which leads to an increase of surface hardness and strength [2]. With this procedure a surface quality similar to the results after grinding for ductile materials can be reached [3].

In comparison to other finishing processes burnishing has the advantage that it can be applied on conventional turning and milling machines without great investments. Furthermore a variety of different surface structures, which are only limited by the geometry of the burnishing tool and the machine kinematics, can be processed.

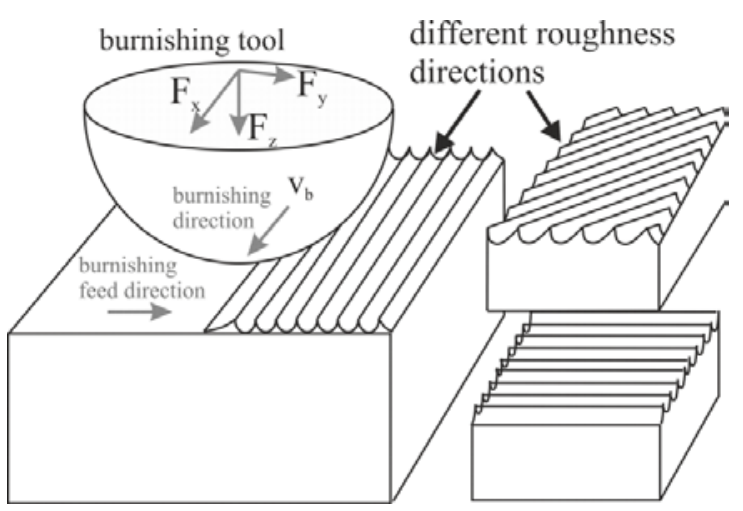

Fig. 2. Schematics of a burnishing process on a plain surface 
Additionally it is a chipless process in which only a negligibly small amount of heat is introduced into the workpiece. As seen in Fig. 2 the process can be adapted from rotationally symmetrical to prismatic parts, because of its potentially high flexibility and the produced positive material properties [4].

Because of the different kinematics of turning in comparison to milling the direction of the roughnessgrooves is not constant [5].Therefore the influence of the different parameters of the burnishing and the structure of the pre-machined surface will be studied.

The aim of presented investigations is to show and interpret the dependencies between the surface structure before and after the burnishing process and the influence of the process forces. Because residual stresses are not easily measurable the finite element method (FEM) is often utilized for stress and strain analysis in burnishing [6]. FEM studies of the burnishing process can be done in $2 \mathrm{D}$ [7] or $3 \mathrm{D}$ [8], but do not necessarily lead to the same results [9]. In this paper a 2D-FEM was applied to analyse stresses during and after the burnishing process.

\section{Experimental Investigations}

A tool concept for a 3-axis milling machine was developed for the investigation of the dependency between the surface structure before and after the burnishing process. The main components of the burnishing tool are a spherical dome made out of diamond with a diameter of $10 \mathrm{~mm}$ and a spring. The spring is loaded during the process to control the necessary burnishing force. The axis of the burnishing tool was equal to the rotation axis of the main spindle. The workpiece was set on top of a 4 component dynamometer of the type 9272 to measure the forces during the burnishing process. In addition a hydraulic overload protection was used under the force measurement system. As workpiece material the aluminium alloy 3.1645 (EN AW 2007) with a yield strength of $\mathrm{R}_{\mathrm{p} 0.2}=220 \mathrm{MPa}$ and a tensile strength of $\mathrm{R}_{\mathrm{m}}=340 \mathrm{MPa}$ was chosen. The experiments were done utilizing design of experiments consisting of a fractional factorial screening experiment and a t-test. Therefore various factors were investigated. The feed of the cutting process $f_{c}$ was varied to create specific surfaces of the specimen as input for the burnishing process. The kinematic roughness Rt can be calculated and adjusted with the cutting edge corner radius $r_{\varepsilon}$ of the cutting tool by using the Eq. 1 .

$$
R t=f_{c}^{2} /\left(8 r_{\varepsilon}\right)
$$

During the experiments the kinematic pre-roughness only depends on $\mathrm{f}_{\mathrm{c}}$, because $\mathrm{r}_{\varepsilon}$ was kept constant with a value of $0.4 \mathrm{~mm}$. The angle $\gamma_{\mathrm{b}}$ describes the angle between the direction of the pre-machining process (cutting) and the finishing process (burnishing). This factor has been chosen to check whether the direction of the pre-machining has an influence on the burnished surface. In addition the effects of the used lubricant strategy on the burnishing process forces $F_{z}$ were investigated. An increasing forming speed leads to an increasing yield stress and therefore the burnishing speed $\mathrm{v}_{\mathrm{b}}$ was varied to investigate its effects. The burnishing feed $f_{b}$ describes the distance of the parallel burnishing paths. As seen in Eq. 1 the feed has an influence on the kinematic roughness and therefore is used as a factor. The burnishing infeed $\mathrm{a}_{\mathrm{pb}}$ represents the amount whereby the tool is set in $\mathrm{z}$-direction. This causes the spring in the burnishing tool to be loaded and ultimately controls the burnishing forces. The forces in the main directions of the Cartesian coordinate system were measured. Those three measured variables are the force in machining direction $F_{x}$, the force in burnishing feed direction $F_{y}$ and the force $\mathrm{F}_{\mathrm{z}}$ which works perpendicular to the surface. The burnishing infeed $\mathrm{a}_{\mathrm{pb}}$ was to $0.1,1.5$ and $2 \mathrm{~mm}$ resulting in burnishing forces $F_{z}$ of 170,320 and $400 \mathrm{~N}$. Further measurands are the surface-parameters $\mathrm{Ra}$ and $\mathrm{Rz}$, which are specified in DIN EN ISO 4287. All process parameters are listed in Table 1 . The pre-tests were done with a full combination the $1^{\text {st }}$ and $2^{\text {nd }}$ factor for all process parameters. On the basis of the pre-test, additional investigations with focus on burnishing force $F_{z}$, burnishing feed $f_{b}$ and angle between cutting and burnishing $\gamma_{\mathrm{b}}$ were extended by an additional $3^{\text {rd }}$ factor. Those investigations were done with the $1^{\text {st }}$ factor for the process parameters $f_{c}$, lubricant and $v_{b}$. The other parameters were varied according to Table 1 .

Table 1. Factor combinations for the pre- and the main tests

\begin{tabular}{|c|c|c|c|}
\hline factor & $\mathbf{1}^{\text {st }}$ & $\mathbf{2}^{\text {nd }}$ & $\mathbf{3}^{\text {rd }}$ \\
\hline $\mathrm{f}_{\mathrm{c}}$ & $0.36 \mathrm{~mm}$ & $0.18 \mathrm{~mm}$ & - \\
\hline angle $\gamma_{\mathrm{b}}$ & $0^{\circ}$ & $90^{\circ}$ & $45^{\circ}$ \\
\hline lubricant & dry & emulsion & - \\
\hline $\mathrm{V}_{\mathrm{b}}$ & $2 \mathrm{~m} / \mathrm{min}$ & $20 \mathrm{~m} / \mathrm{min}$ & - \\
\hline $\mathrm{f}_{\mathrm{b}}$ & $0.5 \mathrm{~mm}$ & $0.125 \mathrm{~mm}$ & $0.25 \mathrm{~mm}$ \\
\hline $\mathrm{F}_{\mathrm{z}}$ & $170 \mathrm{~N}$ & $320 \mathrm{~N}$ & $400 \mathrm{~N}$ \\
\hline
\end{tabular}

First the surface of the specimen was machined via a cutting process using a loop motion, seen in Fig. 3. A defined and constant surface structure was created and a surface parallel to the burnishing process was ensured by using a constant clamping position. This machined surface is comparable to a turned structure with an infinite radius. The direction of the cutting process is rotated around the z-axis to create the angle between cutting and burnishing process.

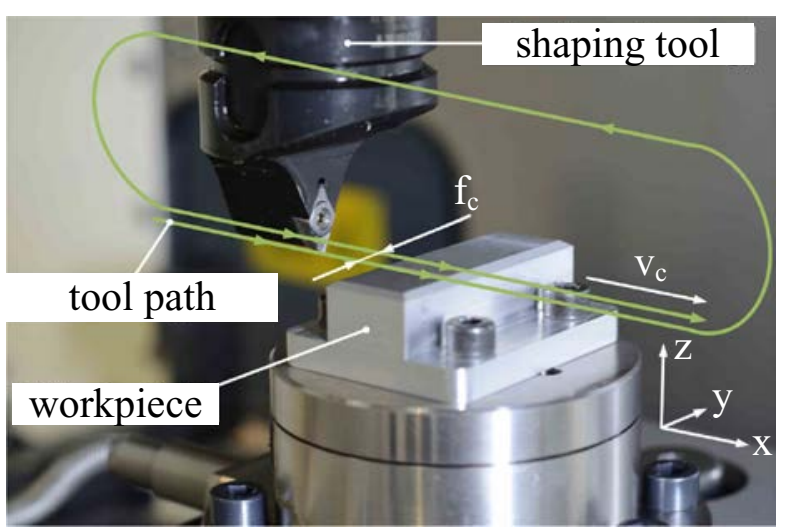

Fig. 3. Experimental setup and kinematics for the cutting 
The burnishing process was done in a similar way to the cutting process as shown in Fig. 4. The only difference was that the direction of the burnishing process was unchanged to ensure the comparability of the force recordings.

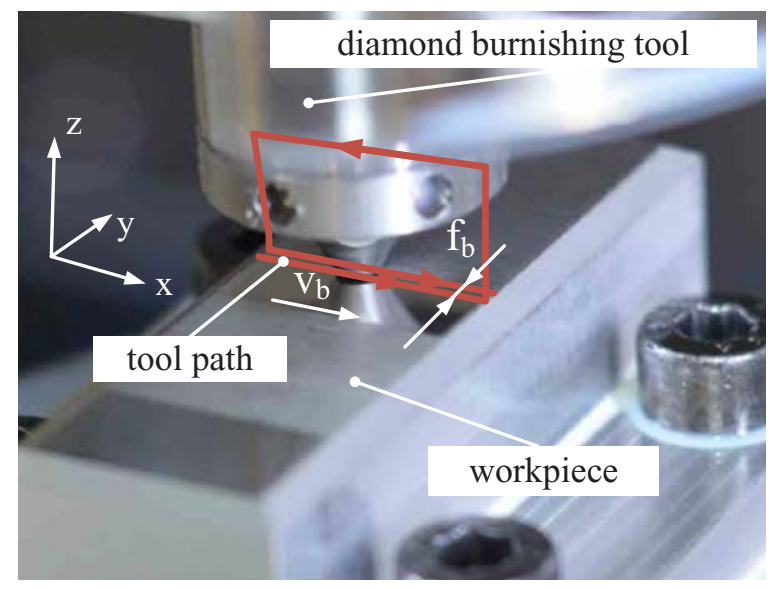

Fig. 4. Experimental setup and kinematics burnishing process

\section{Numerical analysis}

The numerical analysis was done by the finite element method (FEM) using a 2D plain-strain model, which is shown with mesh and boundary conditions in Fig. 6. The burnishing tool was modelled as a ridged sphere with a diameter of $10 \mathrm{~mm}$. The workpiece was a 5 by $30 \mathrm{~mm}$ rectangle modelled as elastic-plastic. EN AW 2007 was used as material, which was present in the material database of the simulation software. A nonlinear plasticity material law and work hardening was used.

As seen in Fig. 5 the ratio of the measured forces $\mathrm{F}_{\mathrm{x}}=41 \mathrm{~N}$ to $\mathrm{F}_{\mathrm{z}}=410 \mathrm{~N}$ was 0.1 . In the simulation the contact between tool and workpiece used a Coulomb friction model with this ratio as friction coefficient. For the creation of a 2D simulation model a methodology similar to Röttger [7] was used. The kinematics of the burnishing process was split in 2 different components, which are the burnishing speed $\mathrm{v}_{\mathrm{b}}$ and the burnishing feed $f_{b}$. Together with the burnishing force $F_{z}$ those three components are perpendicular to each other. The component $\mathrm{f}_{\mathrm{b}}$ and $\mathrm{v}_{\mathrm{b}}$ were observed in separate simulation models, $\mathrm{f}_{\mathrm{b}}$ in model $\mathrm{A}$ and $\mathrm{v}_{\mathrm{b}}$ in model $\mathrm{B}$. For both models the movement is fixed in $\mathrm{z}$-direction and depending on the model a different movement in $\mathrm{x}$ direction is enforced. The movement of model A takes place in three steps, first loading the tool with the force $\mathrm{F}_{\mathrm{z}}$, second unloading the tool and third moving the workpiece by the burnishing feed $f_{b}$.

This procedure is repeated 10 times. The burnishing feed was set to $0.125 \mathrm{~mm}$ and $0.5 \mathrm{~mm}$. The movement in model B takes also place in three steps. The first step is loading the tool with the force $\mathrm{F}_{\mathrm{z}}$, second moving the workpiece with a constant speed $\mathrm{v}_{\mathrm{b}}$ of $20 \mathrm{~m} / \mathrm{min}$ while keeping a constant force $\mathrm{F}_{\mathrm{z}}$ and third unloading the tool. An ideal plain and a rough surface, which was modelled according to the pre-processed surface used during the experiment with a surface roughness of $\mathrm{Rz}=40 \mu \mathrm{m}$, was used for each model. The burnishing force $F_{z}$ was set to $200 \mathrm{~N}$ and $400 \mathrm{~N}$, as seen in Fig. 5. The mesh was divided in to 3 zones with a total of 4000 elements. The first zone is the area of the roughness with an element size of $0.04 \mathrm{~mm}$ (relative element size 0.02 ). The second zone is the contact area between tool and workpiece with an element size of $0.18 \mathrm{~mm}$ (relative element size 0.1 ). The remaining area is modelled with an element size of $1.86 \mathrm{~mm}$ (relative element size 1).

\section{Results}

The aim of the pre-test was to detect the influencing factors on the surface properties and forces. A change of the burnishing infeed $\mathrm{a}_{\mathrm{pb}}$ from $0.1 \mathrm{~mm}$ to $1.5 \mathrm{~mm}$ increases the burnishing force perpendicular to the surface from $170 \mathrm{~N}$ to $400 \mathrm{~N}$, taking the spring constant of the tool and the stiffness of the setup into account. The movement sequence of the machine results in a force diagram, which is shown in Fig. 5. The contact between tool and workpiece surface, where the preload of the spring is overcome is shown in the contact section(1). In the loading section(2) the burnishing force perpendicular to the surface is set by reaching the burnishing infeed. Afterwards the tool is moved in $\mathrm{x}-$ direction in the burnishing section (3) and generates the force in processing $\mathrm{x}$ - and feed $\mathrm{y}$-direction. In the unloading section(4) a fast lifting movement occurs, where the process forces are lifted.

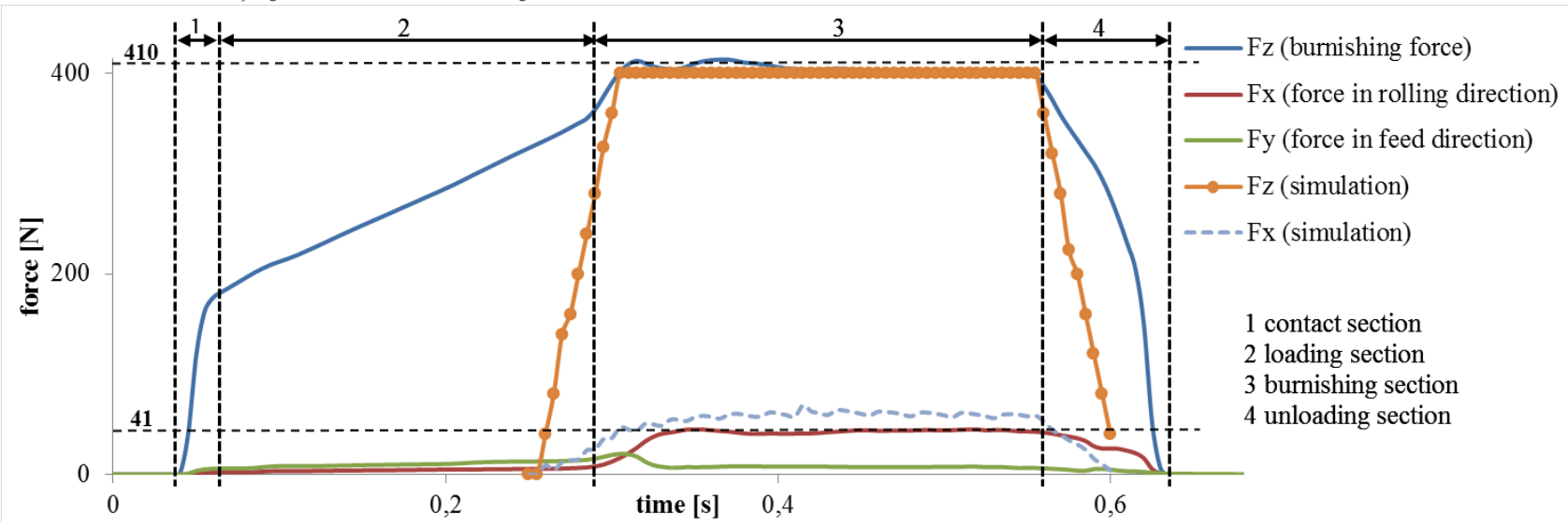

Fig. 5. Different force diagrams during a single burnishing path $\left(f_{c}=0.36 \mathrm{~mm}, \gamma_{b}=90^{\circ}, v_{b}=2 \mathrm{~m} / \mathrm{min}\right.$, dry, $\left.f_{b}=0.125 \mathrm{~mm}\right)$ 


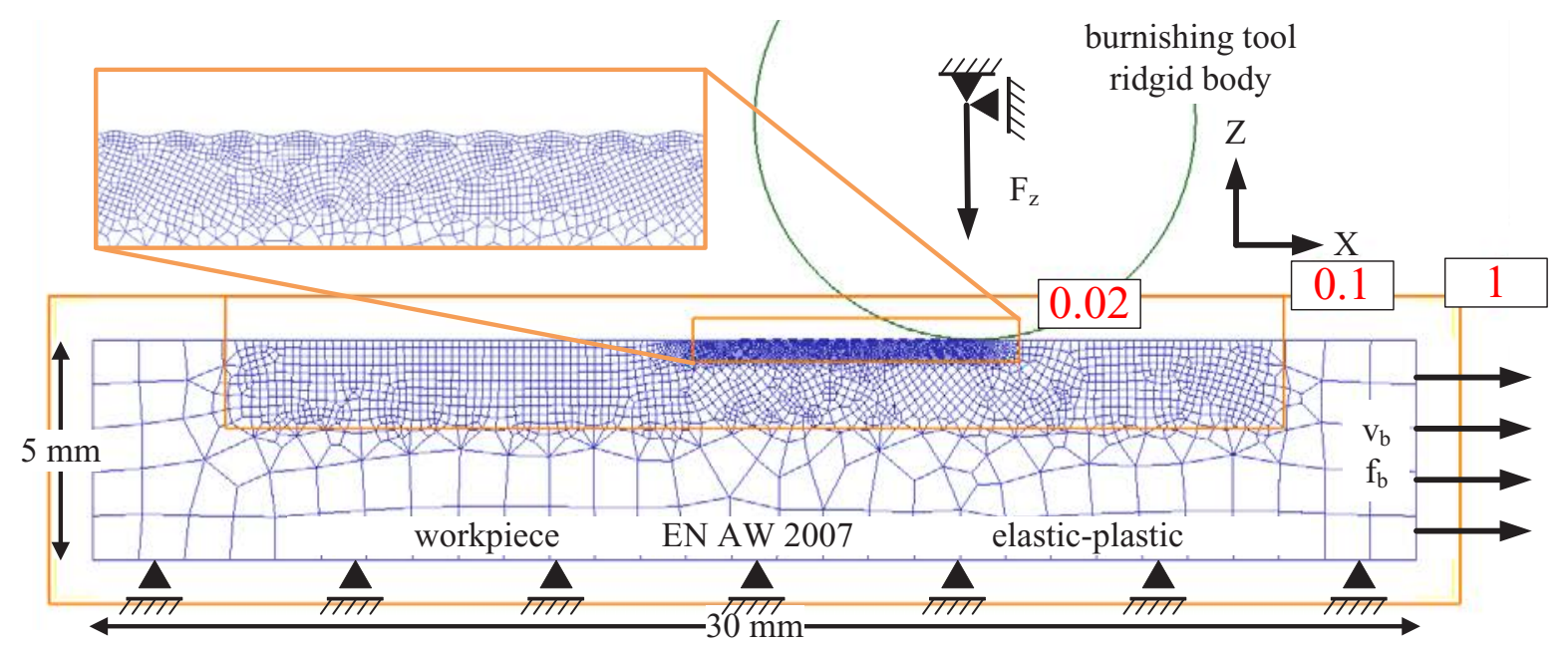

Fig. 6. 2D FEM model for the burnishing simulation with boundary conditions and mesh with three different sizes

In general it can be observed, that the oscillation of the force $\mathrm{F}_{\mathrm{z}}$ in section 3 is damped very well and therefore the process is stable. Furthermore the burnishing forces do not rise during the process, which indicates that the bead stays at constant height. Also cracks and damage to the burnished surface by too large forces is prevented. It was possible to reduce the roughness value $\mathrm{Rz}$ by $0.81 \mu \mathrm{m}$ with an increase in burnishing infeed. On the other hand the roughness value Ra was only reduced by $0.06 \mu \mathrm{m}$. The burnishing feed $\mathrm{f}_{\mathrm{b}}$ has a great influence on the mean value of the roughness profile $\mathrm{Ra}$. A reduction of the factor $\mathrm{f}_{\mathrm{b}}$ from $0.5 \mathrm{~mm}$ to $0.125 \mathrm{~mm}$ reduces the $\mathrm{Ra}$ value by an average of $1.44 \mu \mathrm{m}$ as seen in Fig. 7. A similar relationship can be observed for the roughness value Rz. The factors burnishing infeed $\mathrm{a}_{\mathrm{pb}}$ (and the resulting burnishing force $\mathrm{F}_{\mathrm{z}}$ ), the angle between cutting and burnishing $\gamma_{\mathrm{b}}$ and the roughness of the pre-machined surface only have a small influence on the measured roughness. For example a change of the angle $\gamma_{\mathrm{b}}$ from $0^{\circ}$ to $90^{\circ}$ only reduces the roughness values $\mathrm{Ra}$ by $0.04 \mu \mathrm{m}$ and $\mathrm{Rz}$ by $0.2 \mu \mathrm{m}$, which are within the measurement uncertainty. The factors cutting feed fs, lubricant strategy and burnishing speed $v_{b}$ show no significant effect on the roughness.

The Pearson correlation coefficient $r$ was calculated to show dependencies between the investigated factors and the surface properties. It is a value between -1 and 1 , which show the linear correlation between two investigated variables. In this context $r$ with a value of 0 means no correlation between the variables, whereas -1 or 1 means a negative or positive linear correlation. The error probability $\mathrm{p}$ is a value between 0 and 1 that shows how randomly distributed the investigated variables are. A higher value means a more random distribution and therefore $\mathrm{p}$ has to be lower than 0.05 for the correlation to be valid. The angle between cutting and burnishing $\gamma_{b}$ does not correlate with the roughness values $\mathrm{Ra}$ and $\mathrm{Rz}$ with a $r_{x, y}(R a)=0.008$ and $r_{x, y}(R z)=0.012(p<0.05)$. In the observed range up to $\mathrm{F}_{\mathrm{z}}=400 \mathrm{~N}$ the burnishing infeed $a_{\mathrm{pb}}$ does not have a significant effect on the roughness of the machined surface, but it does have a big impact on all process forces. The burnishing feed $f_{b}$ correlates with most surface values measured according to DIN EN ISO 4287 and DIN EN ISO 13565-2, with values of $r_{x, y}(R a)=0.956$ and $r_{x, y}(R z)=0.94(p<0.05)$. Conclusively the evaluation of the statistical experiments shows that the condition of the pre-processed surface has no significant influence on the roughness after the burnishing process within the frame of the established factors. A correlation with the target values $\mathrm{Ra}$ and $\mathrm{Rz}$ could only be proven for the burnishing feed $\mathrm{f}_{\mathrm{b}}$.

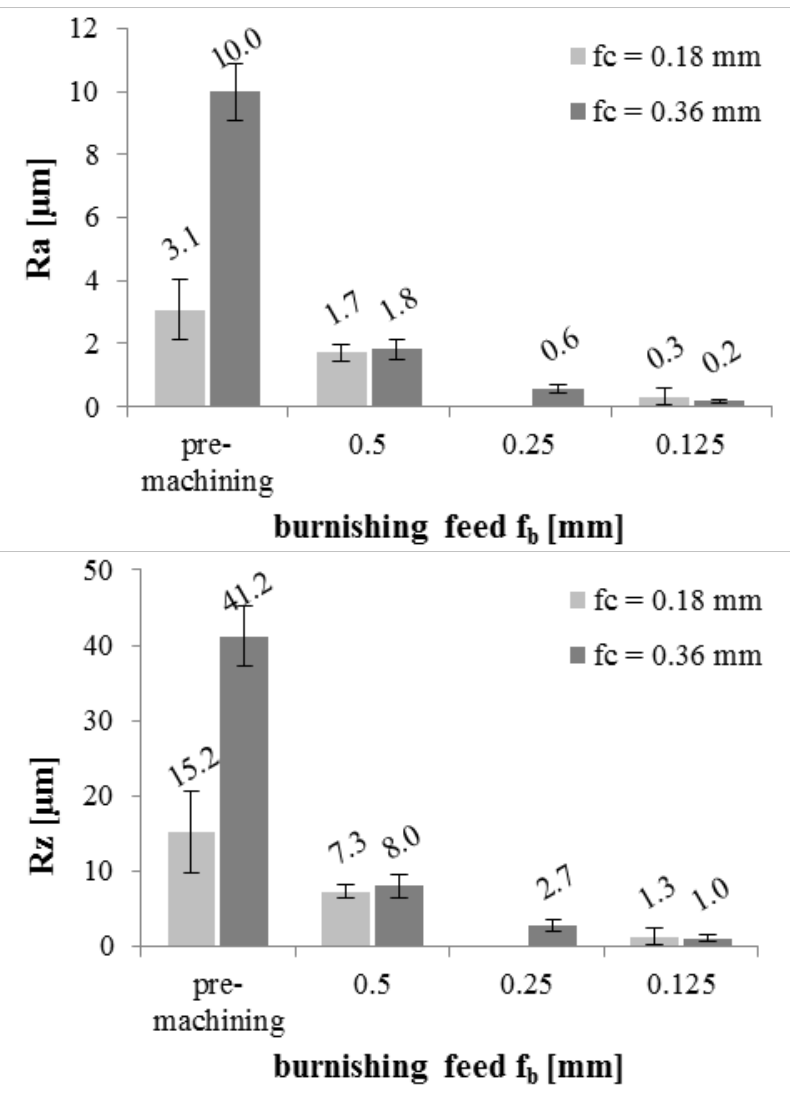

Fig. 7. Results of the target values Ra and $\mathrm{Rz}$ under different burnishing feeds $\left(\gamma_{\mathrm{b}}=90^{\circ}\right.$, dry, $\left.\mathrm{v}_{\mathrm{b}}=2 \mathrm{~m} / \mathrm{min}, \mathrm{F}_{\mathrm{z}}=320 \mathrm{~N}\right)$ 

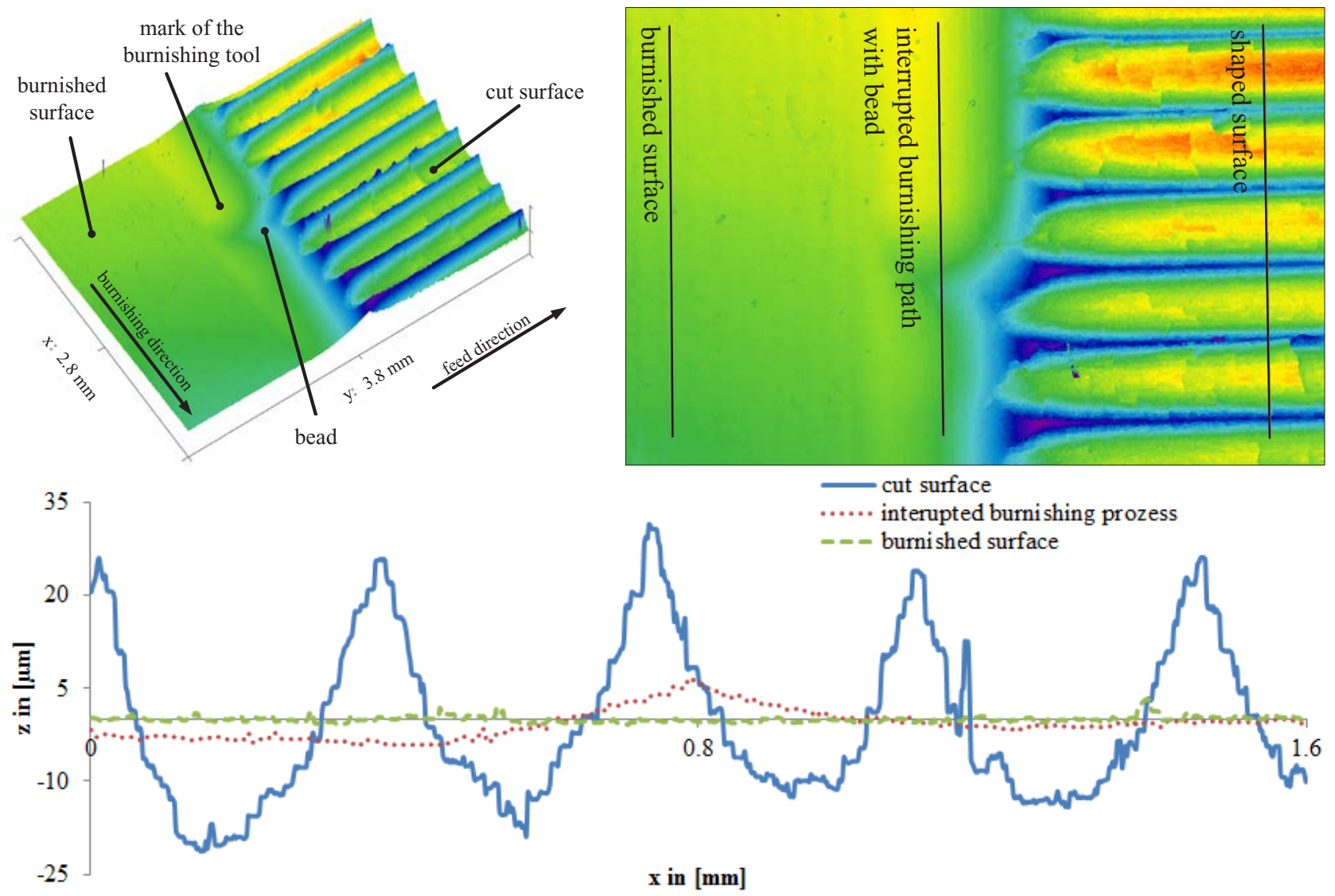

Fig. 8. 3D-measurement of a burnishing process and roughness profiles for three different zones $\left(F_{z}=320 \mathrm{~N}, \mathrm{f}_{\mathrm{b}}=0.125 \mathrm{~mm}\right.$, $\left.\gamma_{\mathrm{b}}=90^{\circ}, \mathrm{f}_{\mathrm{c}}=0.36 \mathrm{~mm}\right)$

In the following the burnishing process was interrupted and their surfaces were optically measured in three dimensions for a detailed process analysis. This graphical representation of the measured surface is seen in Fig. 8 and show the remaining imprint of the burnishing tool after the elastic recovery of the workpiece material.

Due to the difference in height between the interrupted burnishing path and burnished surface it can be stated, that the material "flows" around the tool, but at the same time forms a bead in front of the tool. Therefore the profile tips are not smoothed and the valleys lifted like it is the case with harder materials. Instead a completely new surface structure is created. This supports the statement that the parameters of the pre-process have low influence on the roughness of the surface after the burnishing, especially for such ductile materials like aluminium. The described relationship of the resulting roughness with the burnishing feed $f_{b}$ is also visible by the adjacent burnishing paths.

The aim of the FEM-simulation was to determine the stress and strain distribution during the burnishing process and the residual stresses after the burnishing. An example of the simulation results of model B with the rough surface is seen in Fig. 9. Step I, II and III show the deformation of a single asperity. During all three shown steps the von Mises stress for the asperity is higher than the yield strength of $R_{p 0.2}=220 \mathrm{MPa}$ represented by the area $\mathrm{C}$. Therefore the whole asperity as well as a large area under it is in a state of plastic deformation. The maximum tensile strength of $\mathrm{R}_{\mathrm{m}}=340 \mathrm{MPa}$ is not reached, which means that the workpiece is not damaged. In all done simulations the average maximum von Mises stress under load is $263 \mathrm{MPa}$ with a standard deviation of $14 \mathrm{MPa}$. Higher values of the von Mises stress are reached when the rough surface is present, with an average value of $273 \mathrm{MPa}$. The burnishing of the flat surface reaches an average value of $252 \mathrm{MPa}$. Furthermore the results of the simulation show that the burnishing force does only have a miniscule influence on the maximum von Mises stress. In all simulation cases $\mathrm{R}_{\mathrm{p} 0.2}$ is reached and therefore plastic deformation occurs. It is also possible to apply higher loads in further investigations, because the maximum von Mises stress reached is at around $80 \%$ of $R_{m}$. The diagrams in Fig. 9 show different stresses during and after the process (marked in Step II) in comparison to the depth of the workpiece. After the burnishing process the maximum absolute stress in $\mathrm{x}$-direction is 7.7 times higher than in $\mathrm{z}$-direction. Therefore the stress in $\mathrm{x}$-direction has the most contribution to residual stress after the burnishing process. The stress in $\mathrm{x}$-direction also shows a prominent point where it switches from compressive (negative stress values) to tensile stress (positive stress values). This point is used to determine the depth of the residual stresses. 


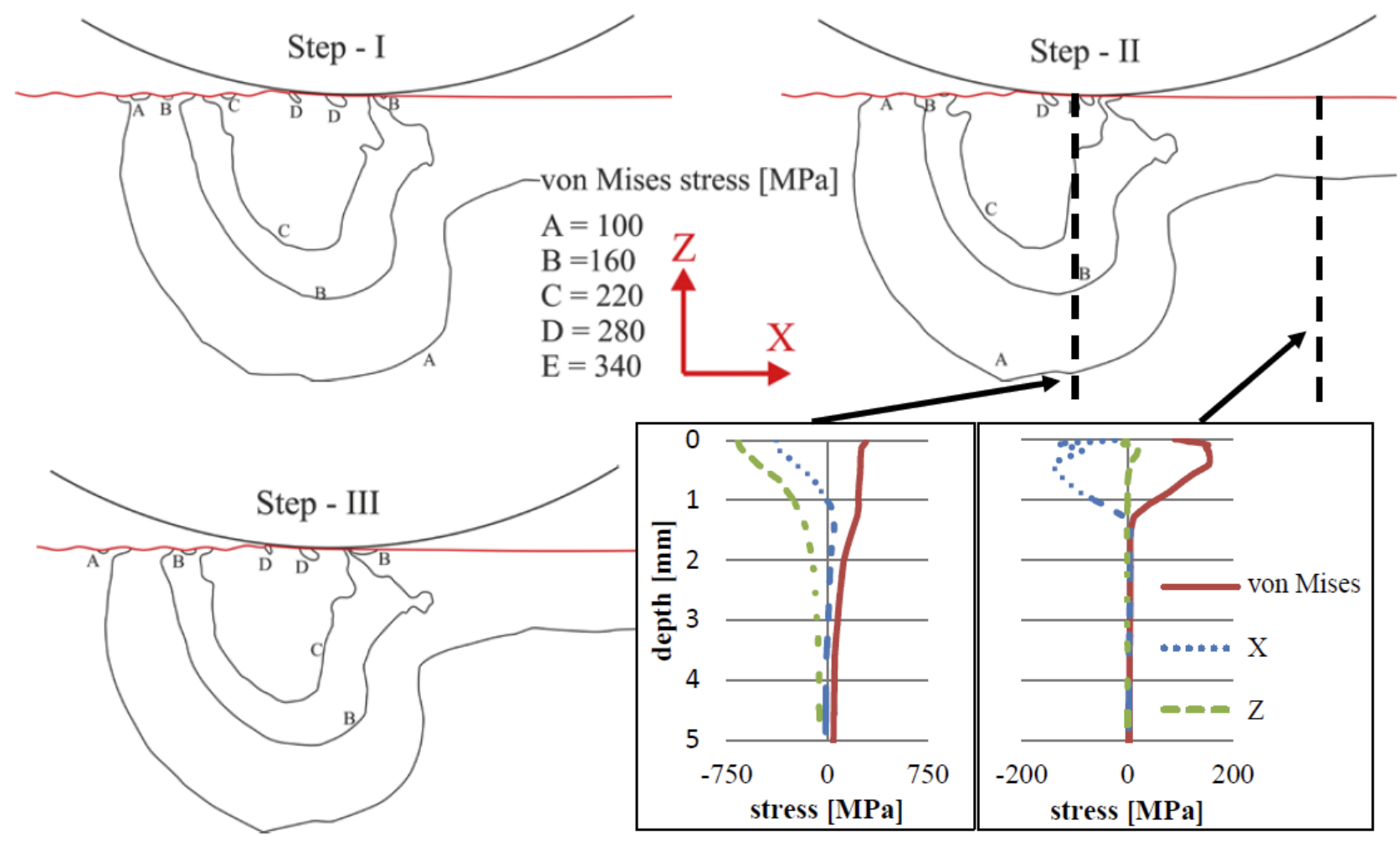

Fig. 9. Step I, II and III: von Mises stress during burnishing, diagrams: von Mises, $x$ - and z-stress during and after burnishing (residual stress) in comparison to the depth of the workpiece $\left(\mathrm{F}_{\mathrm{z}}=400 \mathrm{~N}\right.$, model $\mathrm{B}, \mathrm{v}_{\mathrm{b}}=20 \mathrm{~m} / \mathrm{min}$, pre-machined surface)

The average depth of residual stress is identical between the models $\mathrm{A}$ and $\mathrm{B}$, as well as between a burnishing feed $\mathrm{f}_{\mathrm{b}}$ of $0.125 \mathrm{~mm}$ and $0.5 \mathrm{~mm}$, which means that the type of simulation model and the burnishing feed have no influence on the average depth of the residual stress. However the burnishing force has influence on depth of residual stress. A burnishing force of $200 \mathrm{~N}$ leads to a depth of $0.5 \mathrm{~mm}$ while a force of $400 \mathrm{~N}$ leads to a depth of $1.3 \mathrm{~mm}$. As seen in Fig. 5 the resulting force $F_{x}$ in burnishing direction was at around $50 \mathrm{~N}$. This value is higher than the measured value of the experiments and its cause has to be investigated in further studies.

\section{Conclusion}

The experimental investigation and the numerical analysis of burnishing of EN AW 2007 show that the burnishing direction and surface structure before burnishing have no significant influence on the burnishing process and the investigated surface parameters, especially for such ductile materials like aluminium. Therefore the process can be viewed as direction-independent. The investigation at the surface border area of the process shows that the material forms a constant bead in front of the tool. This behaviour leads to the forming of a new surface, with roughness values manly depending on the burnishing feed.

The stresses during and after the burnishing process were analysed with FEM-simulation. The results show that the maximum von Mises stress during burnishing is nearly independent from the burnishing force, but slightly depends on the surface roughness. Furthermore it was shown, that at the investigated burnishing forces the von Mises stress only reaches the tensile strength of the investigated aluminium by $80 \%$, which means that even higher loads can be applied without damaging the surface. The depth of the residual stress is largely influenced by the applied burnishing force, with higher forces leading to deeper residual stresses. Therefore it is possible to increase the depth of the residual stresses by applying higher forces. Furthermore the experimental investigation also shows, that a two dimensional simulation is not sufficient to reproduce the deformation effects which are present during the burnishing of aluminium.

Further investigations should utilize a 3D FEMsimulation. Also the range of the experimental investigation should be increased by additional factors regarding the burnishing force and structure of the premachined surface. Materials with other properties should be taken into account as well.

The research was funded by the European Union (European Social Fund) and the Free State of Saxony.
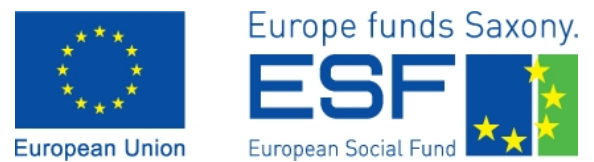

\section{References}

1. W. Degner, Handbuch Feinbearbeitung (1979)

2. F. Grünwald, Fertigungsverfahren in der Gerätetechnik (1985) 
3. U. Virkus, Oberflächengestalltung durch die Verfahrensfolge Spanen - Glattwalzen unter stofflichen, geometrischen und kinematischen Aspekten, Technische Universität Dresden (2001)

4. L. N. López de Lacalle, A. Lamikiz, J. Muñoa, J. A. Sánchez, Int. J. Mach. Tools Manuf. 45, 1659 (2005)

5. L. N. López de Lacalle, A. Rodríguez, A. Lamikiz, A. Celaya, R. Alberdi, Mater. Manuf. Process. 26, 997 (2011)

6. P. Sartkulvanich, T. Altan, F. Jasso, C. Rodriguez, J. Manuf. Sci. Eng. 129, 705 (2007)

7. K. Röttger, „Walzen hartgedrehter Oberflächen“, Technische Hochschule Aachen, 2003.

8. P. Balland, L. Tabourot, F. Degre, V. Moreau, Precis. Eng. 37, 129 (2013)

9. Y.-C. Yen, P. Sartkulvanich, und T. Altan, CIRP Ann. - Manuf. Technol. 54, 237 (2005) 